Review Article

\title{
Yiqi Yangyin Huoxue Method in Treating Idiopathic Pulmonary Fibrosis: A Systematic Review and Meta-Analysis of Randomized Controlled Trials
}

\author{
Min Zhou, ${ }^{1}$ Chao Ye $\mathbb{D}^{2}{ }^{2}$ Qijun Liang ${ }^{D},{ }^{2}$ Qiulan Pei, ${ }^{2}$ Fan Xu, ${ }^{1}$ and Hang Wen ${ }^{3}$ \\ ${ }^{1}$ College of Clinical Medical, Jiangxi University of Traditional Chinese Medicine, Nanchang, China \\ ${ }^{2}$ Affiliated Hospital of Jiangxi University of Traditional Chinese Medicine, Nanchang, China \\ ${ }^{3}$ College of Clinical Medical, Shanghai University of Traditional Chinese Medicine, Shanghai, China
}

Correspondence should be addressed to Chao Ye; yyechao@126.com and Qijun Liang; liangqijun200888@163.com

Received 18 April 2020; Revised 19 July 2020; Accepted 27 July 2020; Published 3 October 2020

Academic Editor: Gioacchino Calapai

Copyright (c) 2020 Min Zhou et al. This is an open access article distributed under the Creative Commons Attribution License, which permits unrestricted use, distribution, and reproduction in any medium, provided the original work is properly cited.

Objective. Idiopathic pulmonary fibrosis (IPF) is a common respiratory disease that can lead to respiratory failure in severe condition. Despite notable advances in its treatment, some patients show poor effect when treated with conventional western medicine (CWM). Traditional Chinese medicine with the Yiqi Yangyin Huoxue method (YQYYHXM) has been reported to be positive for IPF. In order to explore the effectiveness and safety of YQYYHXM in the treatment of IPF, we performed this metaanalysis. Method. We searched six databases including Embase, Cochrane, PubMed, CNKI, Wan Fang, and VIP database from their inception to June 1,2019, and then selected eight studies. Two reviewers independently conducted methodological evaluation and data analysis by the software RevMan 5.3.3 and Stata 12.0. Results. The meta-analysis revealed that when YQYYHXM was adopted in combination with CWM, cough, chest pain, and shortness of breath of IPF patients improved significantly. After treatment with YQYYHXM combined with CWM, the SGRQ of IPF patients substantially enhanced. YQYYHXM also has positive effect on 6MWD and TLC, but the improvement on FVC was not obvious. In addition, YQYYHXM has no significance in improving $\mathrm{PaO}_{2}$. All the adverse events were reported in the control group. Conclusion. YQYYHXM is more effective and safe as adjunctive treatment for patients with IPF. However, in the future, long-term, large-scale, and high-quality trials will be required to provide more convincing evidence of YQYYHXM due to some limitations of this review.

\section{Introduction}

Idiopathic pulmonary fibrosis (IPF) is an interstitial lung disease (ILD) limited to the lung associated with a severe prognosis (mean survival less than 5 years) and a radiological and histopathological pattern of usual interstitial pneumonia (UIP) $[1,2]$. The aetiology of IPF is still unknown, but several studies demonstrated a pathogenetic role for epithelial damage, abnormal senescence, and oxidative stress in IPF [3-6]. Especially, increased oxidative stress might promote disease progression in IPF patients mainly in those who are current and former smokers [7]. Epidemiological data showed that its incidence is 4.6 to 8.65 per 100,000 , and 6000 people are diagnosed annually. It seems to affect males more than females [8-10]. The poor prognosis of IPF is close to the chronically progressive nature of the disease, resulting in an irreversible damage of lung volume and diffusion capacity that leads to respiratory failure development and death. No therapy can modify IPF natural history (with the only exception for lung transplantation), and actually, the objective of the treatment is to stabilise or reduce the disease progression [11]. Pirfenidone and nintedanib are the only antifibrotic drugs approved by the FDA for reducing functional decline, but they are not enough to halt progression of disease $[12,13]$.

With the discovery of multiple coactivated pathways applied in the pathogenesis of IPF, single targeted therapy is unlikely to work well in isolation. To date, combination therapy becomes more and more attractive to apply for 
diagnostic uncertainty and to suppress both profibrotic and proinflammatory pathways at the same time.

Now, there is more and more focus on traditional Chinese medicine (TCM) which is applied for the treatment of respiratory disease more than thousands of years in China [14-16]. Comparatively, TCM is composed of a variety of herb mixtures in one prescription, including a variety of active ingredients, which can work on numerous targets. When combined, they can provide perfect benefit with a moderate effect in a synergistical or antagonistical way [17]. Therefore, TCM has gradually been recognized by the western countries as an complementary treatment drug for IPF and is even widely prescribed as one of the clinical guideline drugs for IPF $[18,19]$. Based on the theory of TCM, the diagnosis of IPF was considered as Feiwei, which was firstly mentioned in Huang Di Nei Jing. The symptom characteristic of Feiwei, such as dry cough, progressive dyspnea, tarsalgia, and unfavorable prognosis, was extremely similar to IPF $[20,21]$.

Based on thousands of years of exploration in clinical experience and summary, the overall pathogenesis of "Feiwei" is deficiency of qi and Yin, and the treatment requires tonifying qi and nourishing Yin. Later, as the research of TCM continues to develop, the famous expert Tianshi Ye put forward the Luo disease theory $[22,23]$. Some new treatments of IPF for supplementing qi, nourishing yin, and promoting blood come into being, but the mechanism is unclear and there is no sufficient evidence to prove it. Therefore, this study summarizes the systematic evaluation of TCM treatments of IPF for tonifying qi, nourishing Yin, and promoting blood, aimed to provide some evidence and reference.

\section{Methods}

2.1. Search Strategy. Six databases including Embase, Cochrane, PubMed, CNKI, Wan Fang, and VIP database were searched from their inception to June 1, 2019. If any, we would try to contact the original study authors to consult the information we need. We would perform a manual search to track the references of relevant literature. The following were the search keywords and terms we used:"idiopathic pulmonary fibrosis" OR "pulmonary fibrosis" OR "pulmonary interstitial fibrosis" OR "idiopathic pulmonary interstitial fibrosis" OR "IPF" OR "Feibi" OR "Feiwei" AND "Yiqi Yangyin" OR "Yiqi Huoxue" OR "Yiqi Yangyin Huoxue" OR "tonifying qi and nourishing Yin" OR "supplementing qi and promoting blood" OR "nourishing Yin and promoting blood" OR "Traditional Chinese medicine" OR "Chinese medicinal herb" OR "Chinese herbal medicine" OR "combination of Chinese traditional and western medicine" OR "TCM" OR "CHM" AND "randomized controlled trial" OR "randomized trial" OR "controlled clinical trial" OR "clinical research" OR "randomized trial."

\subsection{Inclusion and Exclusion Criteria}

\subsubsection{Inclusion Criteria}

(1) Studies: clinical randomized controlled trials.

(2) Participants: the patients diagnosed with IPF according to the clinical diagnostic criteria referred to
"Guidelines for the Diagnosis and Treatment of Idiopathic Pulmonary Fibrosis in 2002" [24]. There were no limitations on the patient's gender, race, age, and the course and severity of the disease.

(3) Interventions: the experimental group was treated with YQYYHXM (decoction or injection and pill) or combined with CWM (conventional western medicine treatment included steroid, acetylcysteine, antibiotics, or noninvasive ventilator-assisted respiratory therapy). And the control group was treated with CWM alone. There was no limitation on course of treatment.

(4) Outcomes: the primary outcomess included the changes of TCM symptoms (including changes of cough, changes of chest pain, and changes in shortness of breath) according to Guiding Principles of Clinical Research on New Chinese Medicine in 2002 [25].

The secondary outcomes were forced vital capacity (FVC) and total lung capacity(TLC); partial pressure of oxygen in blood $(\mathrm{PaO} 2)$; 6-minute walk test distance (6MWT), St. George's Respiratory Questionnaire scores related to health-related quality of life (SGRQ score), and adverse events.

\subsubsection{Exclusion Criteria}

(1) Duplicate literatures.

(2) Animal experiments, mechanism research, experience, protocols, and case reports.

(3) Literatures on other TCM therapies, for example, acupuncture, asiontophoresis, massage, and acupoint application.

(4) Low-quality literature.

2.3. Data Abstraction. Based on the inclusion and exclusion criteria, information was filtered and extracted from all included literatures after a comprehensive search by two independent researchers (Min Zhou and Fan $\mathrm{Xu}$ ). If any, we would consult the third researcher (Qijun Liang) with specific details to resolve discrepancies to make sure to exclude all errors. The selected data included the first author, year of publication, baseline characteristics, intervention methods, duration, outcomes, and classification of disease severity referred to the scoring system of IPF [26] ( ${ }^{\prime} 92=$ severe; $<91$ and $>66=$ moderate; $\leq 65=$ light).

2.4. Quality Assessment. The assessment was performed by RevMan 5.3.3 according to the cochrane handbook [27]. The overall assessment was based on details including random sequence generation, allocation hiding, incomplete data, selective reporting, and other bias. If the corresponding details were adequately provided, the risk of bias would be graded to be "low"; otherwise, the risk of bias would be graded to be "high." If the relevant entry was not presented, it would be assessed to be "unclear." 
2.5. Statistical Analysis. We performed the meta-analyses by RevMan 5.3.3 and Stata 12.0 software. In this meta-analysis, we would apply the odds ratio (OR) and the mean difference (MD) to assess dichotomous and continuous variable outcomes with a $95 \%$ confidence interval (CI). If $P<0.05$, it was considered statistically significant. We would use the heterogeneity to evaluate the effect, there was no heterogeneity $\left(P>0.1\right.$ or $\left.I_{2}<50 \%\right)$, and we would adopt the fixed effect model for the analysis; otherwise, we would use the randomeffects model. We would adopt sensitivity analysis to evaluate the impact of the inclusion study on outcome. And Egger's test was conducted to assess potential publication bias. If $P<0.05$, this was considered to be of statistical significance. Finally, we adopted the GRADE approach to evaluate the degree of the evidence so as to make our results more convincing.

2.6. Quality of Evidence. In this study, we would adopt the GRADE approach to evaluate the degree of the evidence in order to make our results more evidence-based and credible.

\section{Results}

3.1. Selection of Study. A total of 468 potential articles were collected from their inception to June 1, 2019, with extensive search and collection. After duplicates removed by EndNote X7 software, 216 literatures remained. We excluded 165 literatures with comprehensive reasons by screening the title and abstract. 51 literatures remained. After browsing the full-text articles, we excluded 43 articles for the following reasons: without YQYYHXM, not RCT, and without the data we need. Finally, 8 studies [28-35] were collected in this review (Figure 1).

3.2. Characteristics of the Eligible Studies. The characteristics of all included studies are summarized in Table 1. All the studies were carried out in China. The sample sizes of these trials ranged from 30 to 120 . Treatment duration was from 2 to 12 weeks. The average age was between 55 and 70 . The details of illness degree showed that most of the patients had a moderate degree of illness. The experimental group of all the studies was YQYYHXM combined with CWM, only 6 of which were treated with YQYYHXM in the form of decoction, 1 of which was performed with YQYYHXM in the form of injection, and 1 of which was conducted with YQYYHXM in the form of pill. The control group was treated with CWM such as steroid or acetylcysteine, 4 studies of the control group were treated with steroid therapy, and 4 were treated with acetylcysteine.

3.3. Description of YQYYHXM. Table 2 describes the specific medicine of the prescriptions. It demonstrates the characteristics of the 8 different formulas researched in the total 8 trials. The partial high frequency Chinese herbs are shown in Table 3. These high-frequency drugs can be classified into three categories according to their characteristic: the herbs of nourishing qi: astragalus, Radix Pseudostellariae, ginseng, and American ginseng; the medicine of nourishing Yin: Adenophora stricta Miq, Radix Ophiopogonis, Radix Rehmanniae Praeparata, and Radix Scrophulariae; the medicine of activating blood: ligustrazine, Clematis root, Rhizoma Sparganii, Zedoary, Salviae miltiorrhiza, Peach kernel, Safflower, and so on. The partial high frequency herbs are Huangqi $(n=5$; rate $=63 \%)$, Weilingxian $(n=4$; rate$=50 \%)$, Maidong $(n=3 ;$ rate $=38 \%)$, Danshen $(n=3$; rate $=38 \%)$, Sanleng $(n=3$; rate $=38 \%)$, and Ezhu $(n=3$; rate $=38 \%)$. There is a summary of common medicines in Table 3, which is a partial representation of tonifying qi, nourishing yin, and invigorating blood, respectively.

3.4. Quality Assessment. The risk of bias (ROB) was conducted according to the Cochrane criteria. Two studies $[30,32]$ only mentioned randomization, but did not elaborate on specific randomization methods which were assessed as "unclear." Six studies [28, 29, 31, 33-35] reported the numerical randomization method with a low risk of bias; of those, one study [28] performed numerical randomization using SAS.6.12 statistical software. Only one study [29] mentioned allocation concealment which was graded as "low"; others did not report the allocation concealment, and they were evaluated as "unclear." Additionally, none of the studies involved double blindness in a "high" risk of bias. Four studies [29, 30, 32, 35] described the absence of data during the follow-up; because the number was small, the risk of bias was low. Dropouts were described in five studies [30-32, 34, 35] with the details including quantity and reason in a low risk, which partly was blamed for poor compliance. Three studies [28, 32, 35] reported adverse reactions and described them in detail. All the trials did not involve any other bias in a low risk (Figures 2 and 3).

\subsection{Evaluation of Meta-Analysis}

\subsubsection{The Primary Outcomes}

(1) Change of Cough. The mean difference (MD) was applied for the analyses according to the 6 included RCTs $[28,29,32-35]$. Data extracted showed that the heterogeneity among the RCTs was obvious (chi-square $=19.78$, $P=0.001, I^{2}=75 \%$ ), and the random-effects model was used. And the data analysis results illuminated that the YQYYHXM was superior than CWM $(\mathrm{MD}=-0.71,95 \%$ $\mathrm{CI}=[-1.21,0.21], \quad P=0.005)$. The aggregated analysis revealed that there was statistical significance of YQYYHXM combined with steroid compared with steroid alone (chisquare $=1.29, I^{2}=0 \%, \mathrm{MD}=-0.81,95 \% \mathrm{CI}=[-1.16,0.47]$, $P<0.00001)$. However, it was of no statistical difference for YQYYHXM combined with acetylcysteine compared with acetylcysteine alone $(P=0.32)$ (Figure 4$)$.

(2) Changes of Chest Pain. 5 literatures [28, 29, 32, 33, 35] reported the changes of chest pain of SGRQ. And our pooled results showed that the heterogeneity among the RCTs was not found (chi-square $=1.06, P=0.90, I^{2}=0 \%$ ), and the 


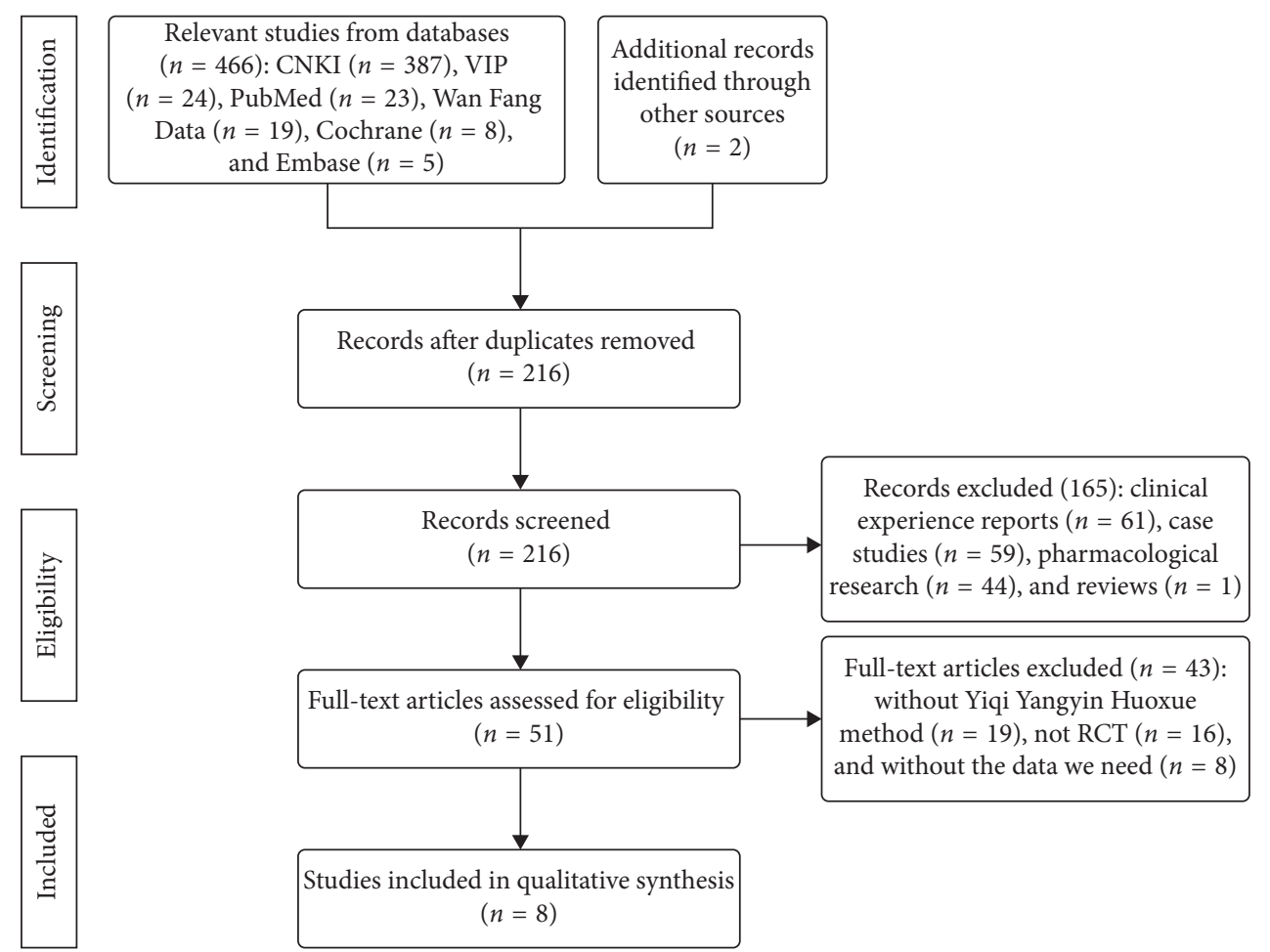

Figure 1: Flow diagram of the study.

fixed-effects model illuminated that the YQYYHXM was superior than CWM $(\mathrm{MD}=-0.46,95 \% \mathrm{CI}=[-0.70,0.21]$, $P=0.0002$ ). Further subgroup analysis revealed that there was statistically significance of YQYYHXM combined with steroid compared with steroid alone (chi-square $=0.67$, $\left.I^{2}=0 \%, \mathrm{MD}=-0.42,95 \% \mathrm{CI}=[-0.69,-0.15], P=0.002\right)$ and acetylcysteine $\quad\left(\mathrm{MD}=-0.62, \quad 95 \% \quad \mathrm{CI}=\left[\begin{array}{ll}-1.18, & -0.06\end{array}\right]\right.$, $P=0.03$ ) (Figure 5).

(3) Changes in Shortness of Breath. 6 literatures $[28,29,31-33,35]$ conducted data analysis of SGRQ score. Findings suggest that the heterogeneity among the RCTs was obvious (chi-square $=12.42, P=0.03, I^{2}=60 \%$ ), and the random-effects model was used. And the data analysis results illuminated that the YQYYHXM combined CWM was superior than $\mathrm{CWM}$ alone $(\mathrm{MD}=-0.38,95 \% \mathrm{CI}=$ $[-0.62,-0.14], P=0.002)$. The aggregated analysis revealed that there was statistical significance of YQYYHXM combined with steroid compared with steroid alone (chisquare $=6.55, \quad I^{2}=54 \%, \quad \mathrm{MD}=-1.14,95 \% \mathrm{CI}=[-1.93$, -0.36], $\quad P=0.004)$ and acetylcysteine alone (chisquare $=1.88, I^{2}=47 \%, \quad \mathrm{MD}=-0.30,95 \% \mathrm{CI}=[-0.55$, $-0.05], P=0.02$ ) (Figure 6).

\subsection{The Secondary Outcomes}

3.6.1. FVC. Four studies $[29,31,32,35]$ provided the data of FVC. Intuitive data showed that the heterogeneity among the RCTs was obvious (chi-square $=1.26, P=0.74, I^{2}=0 \%$ ), and the random-effects model was adopted. The data analysis results illuminated that YQYYHXM combined
CWM had no advantage compared with CWM alone $(\mathrm{MD}=1.52,95 \% \mathrm{CI}=[-2.72,5.76], \quad P=0.48)$. Further subgroup analysis revealed that there was no statistical significance of YQYYHXM combined with steroid $(P=0.25)$ and acetylcysteine $(P=0.82)$ (Figure 7$)$.

3.6.2. TLC. Five studies [29-33, 35] reported the TLC. Our pooled results suggested that the heterogeneity among the RCTs was not found (chi-square $=1.76, P=0.88, I^{2}=0 \%$ ), and the fixed-effects model was adopted. The aggregated analysis illuminated that YQYYHXM combined CWM was superior than $\mathrm{CWM}$ alone $(\mathrm{MD}=-2.22,95 \% \mathrm{CI}=$ $[-4.20,-0.24], P=0.03)$. The subgroup analysis revealed that the combination of YQYYHXM and steroid was proved to be more efficient in enhancing TLC than steroid alone (chi-square $=1.20, I^{2}=0 \%, \mathrm{MD}=-2.64,95 \% \mathrm{CI}=$ $[-4.97,-0.32], P=0.03)$. However, there was no statistically significant difference between YQYYHXM combined with acetylcysteine and acetylcysteine alone $(P=0.56)$ (Figure 8).

3.6.3. $\mathrm{PaO}_{2}$. Four literatures $[29,32,33,35]$ performed the data analysis of $6 \mathrm{MWD}$. The heterogeneity among the RCTs was not found (chi-square $=5.44, P=0.14, I^{2}=45 \%$ ), and the fixed-effects model suggested that YQYYHXM combined CWM had no statistical significance compared with CWM alone $(P=0.08)$. Further subgroup analysis revealed that there was no statistical difference in YQYYHXM combined with steroid $(P=0.06)$ and acetylcysteine $(P=0.91)$ (Figure 9). 


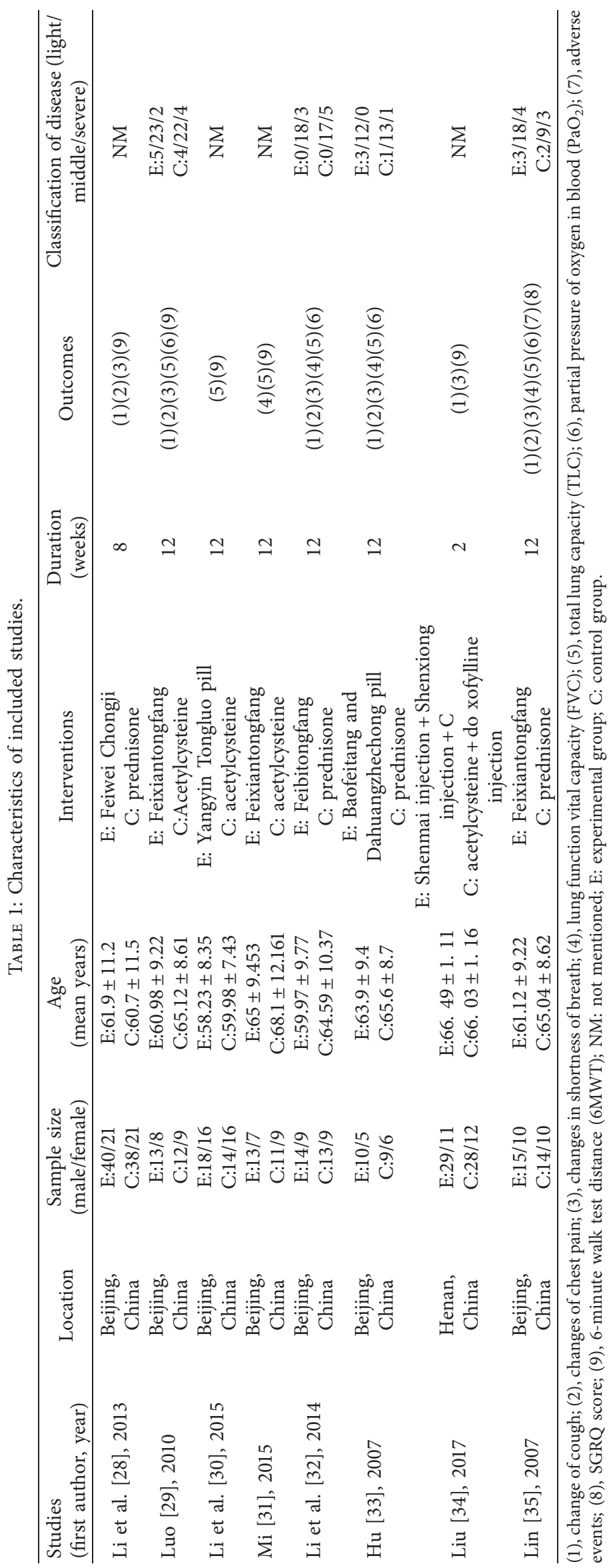


TABle 2: Description of the prescriptions.

\begin{tabular}{|c|c|c|c|c|}
\hline $\begin{array}{l}\text { First } \\
\text { author }\end{array}$ & Formula & Ingredient (Latin name) & Chinese name & $\begin{array}{l}\text { Dosage } \\
(\mathrm{g})\end{array}$ \\
\hline $\begin{array}{l}\text { Li et al. } \\
{[28]}\end{array}$ & $\begin{array}{l}\text { Feiwei } \\
\text { Chongji }\end{array}$ & $\begin{array}{l}\text { (1) Panax quinquefolius L. } \\
\text { (2) Panax notoginseng (Burk) F. H. Chen } \\
\text { (3) Cornus officinalis Sieb. et Zucc } \\
\text { (4) Schisandra chinensis } \\
\text { (5) Aster tataricus L.f. } \\
\text { (6) Ophiopogon japonicus (L.f.) Ker Gawl } \\
\text { (7) Ginkgo biloba L. } \\
\text { (8) Glycyrrhiza uralensis Fisch. }\end{array}$ & $\begin{array}{l}\text { (1) Xiyangshen } \\
\text { (2) Sanqifen } \\
\text { (3) Shanyurou } \\
\text { (4) Wuweizi } \\
\text { (5) Ziwan } \\
\text { (6) Maidong } \\
\text { (7) Yinxingye } \\
\text { (8) Zhigancao }\end{array}$ & $\begin{array}{c}15 \\
3 \\
15 \\
15 \\
15 \\
15 \\
10 \\
10 \\
\end{array}$ \\
\hline Luo [29] & Feixiantong & $\begin{array}{l}\text { (1) Astragalus membranaceus } \\
\text { (2) Rhodiola crenulata (Hook. f. et Thoms.) H. Ohba } \\
\text { (3) Clematis du sis Osbeck } \\
\text { (4) Pumice stone } \\
\text { (5) Sparganium stoloniferum Buch.-Ham } \\
\text { (6) Inula japonica Thunb. } \\
\text { (7) Curcuma phaeocaulis Val. } \\
\text { (8) Rehmannia glutinosa Libosch } \\
\text { (9) Glycyrrhiza uralensis Fisch. }\end{array}$ & $\begin{array}{l}\text { (1) Shenghuangqi } \\
\text { (2) Hongjingtian } \\
\text { (3) Weilingxia } \\
\text { (4) Haifushi } \\
\text { (5) Sanleng } \\
\text { (6) Xuanfuhua } \\
\text { (7) Ezhu } \\
\text { (8) Shengdihuang } \\
\text { (9) Gancao }\end{array}$ & $\begin{array}{l}30 \\
15 \\
12 \\
15 \\
10 \\
15 \\
10 \\
30 \\
6\end{array}$ \\
\hline $\begin{array}{l}\text { Li et al. } \\
{[30]}\end{array}$ & $\begin{array}{l}\text { Yangyin Yife } \\
\text { Tongluo pill }\end{array}$ & $\begin{array}{l}\text { (1) Astragalus membranaceus } \\
\text { (2) Panax quinquefolius L } \\
\text { (3) Stemona sessilifolia (Miq.) Miq. } \\
\text { (4) Ophiopogon japonicus (L.f.) Ker Gawl } \\
\text { (5) Fritillaria cirrhosa D.Don } \\
\text { (6) Paeonia lactiflora Pall } \\
\text { (7) Scrophularia ningpoensis Hemsl } \\
\text { (8) Citrus reticulate Blanco } \\
\text { (9) Salvia miltiorrhiza Bge } \\
\text { (10) Amygdalus persica (L.) Batsch } \\
\text { (11) Saposhnikovia divaricata (Turcz.) Schischk } \\
\text { (12) Ligustrum lucidum Ait. } \\
\text { (13) Gekko gecko Linnaeus }\end{array}$ & $\begin{array}{l}\text { (1) Huangqi } \\
\text { (2) Xiyangshen } \\
\text { (3) Baizhu } \\
\text { (4) Maidong } \\
\text { (5) Chuanbeimu } \\
\text { (6) Chishao } \\
\text { (7) Xuanshen } \\
\text { (8) Juhong } \\
\text { (9) Danshen } \\
\text { (10) Taoren } \\
\text { (11) Fangfeng } \\
\text { (12) Nvzhenzi } \\
\text { (13) Gejie }\end{array}$ & $\begin{array}{l}6 \mathrm{~g} \text { per } \\
\text { pill }\end{array}$ \\
\hline Mi [31] & Feixiantong & $\begin{array}{l}\text { (1) Astragalus membranaceus (Fisch.) Bunge } \\
\text { (2) Carapax Trionycis } \\
\text { (3) Clematis du sis Osbeck } \\
\text { (4) Pumice stone } \\
\text { (5) Sparganium stoloniferum Buch.-Ham } \\
\text { (6) Inula japonica Thunb. } \\
\text { (7) Curcuma phaeocaulis Val. } \\
\text { (8) Rehmannia glutinosa Libosch } \\
\text { (9) Glycyrrhiza uralensis Fisch. }\end{array}$ & $\begin{array}{l}\text { (1) Shenghuangqi } \\
\text { (2) Biejia } \\
\text { (3) Weilingxian } \\
\text { (4) Haifushi } \\
\text { (5) Sanleng } \\
\text { (6) Xuanfuhua } \\
\text { (7) Ezhu } \\
\text { (8) Shengdihuang } \\
\text { (9) Gancao }\end{array}$ & $\begin{array}{c}30 \\
10 \\
12 \\
15 \\
10 \\
15 \\
10 \\
30 \\
6 \\
\end{array}$ \\
\hline $\begin{array}{l}\text { Liu et al. } \\
{[32]}\end{array}$ & Feibitongfang & $\begin{array}{l}\text { (1) Clematis du sis Osbeck } \\
\text { (2) Astragalus membranaceus (Fisch.) Bunge var. } \\
\text { mongholicus (Bunge) P.K.Hsiao } \\
\text { (3) Ligusticum chuanxiong Hort. } \\
\text { (4) Glehnia littoralis Fr. Schmidt ex Miq. } \\
\text { (5) Stemona sessilifolia (Miq.) Miq. } \\
\text { (6) Aster tataricus L.f } \\
\text { (7) Glycyrrhiza uralensis Fisch. }\end{array}$ & $\begin{array}{l}\text { (1) Weilingxian } \\
\text { (2) Huangqi } \\
\text { (3) Chuanxiong } \\
\text { (4) Shashen } \\
\text { (5) Baibu } \\
\text { (6) Ziwan } \\
\text { (7) Gancao }\end{array}$ & $\begin{array}{l}15 \\
20 \\
10 \\
20 \\
10 \\
10 \\
10\end{array}$ \\
\hline $\mathrm{Hu}$ [33] & $\begin{array}{l}\text { Baofeitang and Dahuangzhec } \\
\text { hong pill }\end{array}$ & $\begin{array}{l}\text { (1) Salvia miltiorrhiza Bge } \\
\text { (2) Ophiopogon japonicus (L.f) Ker Gawl } \\
\text { (3) Schisandra chinensis (Turcz.) Baill } \\
\text { (4) Angelica sinensis (Oliv.) Diels } \\
\text { (5) Fritillaria thunbergii Miq. } \\
\text { (6) Sophora flavescens Ait. } \\
\text { (7) Spina Gleditsiae } \\
\text { (8) Pinellia ternata (Thunh.) Breit. }\end{array}$ & $\begin{array}{l}\text { (1) Dangshen } \\
\text { (2) Maidong } \\
\text { (3)Wuweizi } \\
\text { (4) Danggui } \\
\text { (5) Zhebei } \\
\text { (6) Kushen } \\
\text { (7) Zaoci } \\
\text { (8) Banxia }\end{array}$ & NM \\
\hline $\operatorname{Li}[34]$ & SFJ and SXJ & $\begin{array}{l}\text { (1) Panax ginseng C.A.Mey } \\
\text { (2) Aconitum carmichaelii Debx. } \\
\text { (3) Salvia miltiorrhiza Bge } \\
\text { (4) Ligusticum chuanxiong Hort. }\end{array}$ & $\begin{array}{l}\text { (1) Renshen } \\
\text { (2) Fuzhi } \\
\text { (3) Danshen } \\
\text { (4) Chuanxiong }\end{array}$ & NM \\
\hline
\end{tabular}


TABLE 2: Continued.

\begin{tabular}{|c|c|c|c|c|}
\hline $\begin{array}{l}\text { First } \\
\text { author }\end{array}$ & Formula & Ingredient (Latin name) & Chinese name & $\begin{array}{l}\text { Dosage } \\
(\mathrm{g})\end{array}$ \\
\hline Lin [35] & Feixiantong & $\begin{array}{l}\text { (1) Astragalus membranaceus (Fisch.) Bunge var. } \\
\text { mongholicus (Bunge) P.K.Hsiao } \\
\text { (2) Carapax Trionycis } \\
\text { (3) Clematis du sis Osbeck } \\
\text { (4)Pumice stone } \\
\text { (5) Sparganium stoloniferum Buch.-Ham } \\
\text { (6) Inula japonica Thunb. } \\
\text { (7) Curcuma phaeocaulis Val. } \\
\text { (8) Rehmannia glutinosa Libosch } \\
\text { (9) Glycyrrhiza uralensis Fisch. }\end{array}$ & $\begin{array}{l}\text { (1) Shenghuangqi } \\
\text { (2) Biejia } \\
\text { (3) Weilingxian } \\
\text { (4) Haifushi } \\
\text { (5) Sanleng } \\
\text { (6) Xuanfuhua } \\
\text { (7) Ezhu } \\
\text { (8) Shengdihuang } \\
\text { (9) Gancao }\end{array}$ & NM \\
\hline
\end{tabular}

SFJ: Renshen Fuzhi injection; SXJ: Danshen Chuanxiong injection; NM: not mentioned.

TABLE 3: Frequency statistics of herbs that appeared in eight trials.

\begin{tabular}{|c|c|c|c|c|}
\hline Scientific name & Chinese name & Frequency & Rate $(\%)$ & TCM diagnosis \\
\hline Astragalus membranaceus (Fisch.) Bunge var.mongholicus (Bunge) P.K.Hsiao & Huangqi & 5 & 63 & Qi deficiency \\
\hline Clematis du sis Osbeck & Weilingxian & 4 & 50 & Blood stasis \\
\hline Ophiopogon japonicus (L.f) Ker Gawl & Maidong & 3 & 38 & Yin deficiency \\
\hline Salvia miltiorrhiza Bge & Danshen & 3 & 38 & Blood stasis \\
\hline Sparganium stoloniferum Buch.-Ham & Sanleng & 3 & 38 & Blood stasis \\
\hline Curcuma phaeocaulis Val. & Ezhu ${ }^{\circ}$ & 3 & 38 & Blood stasis \\
\hline
\end{tabular}

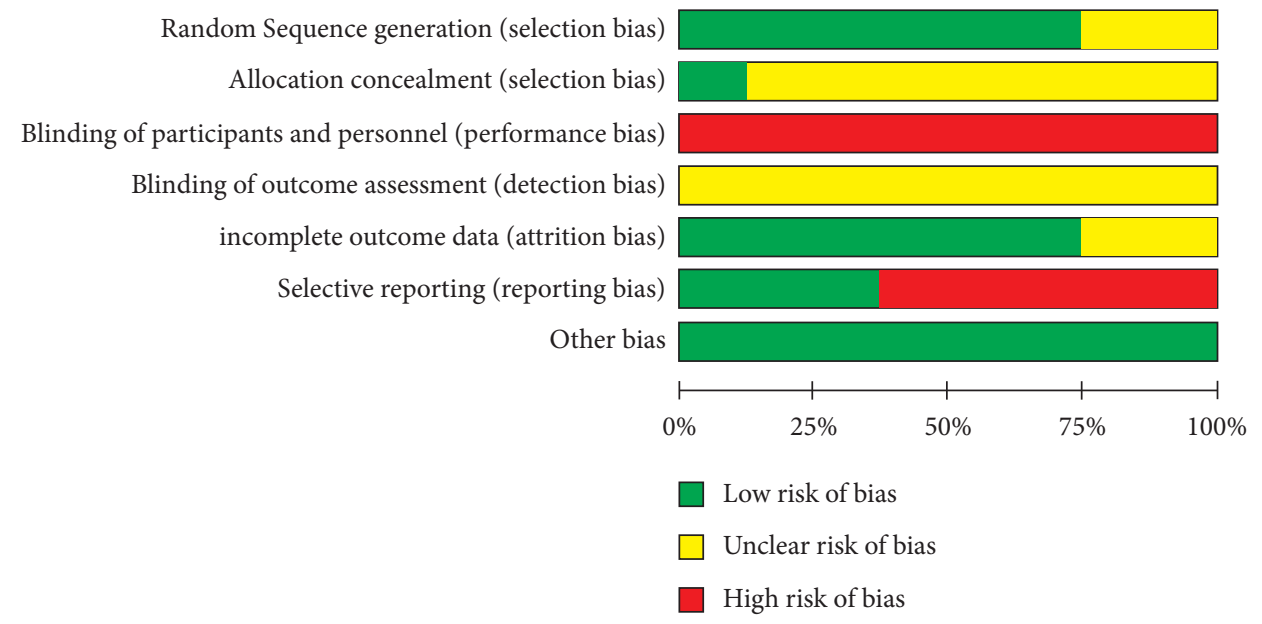

FIgURE 2: Risk of bias graph.

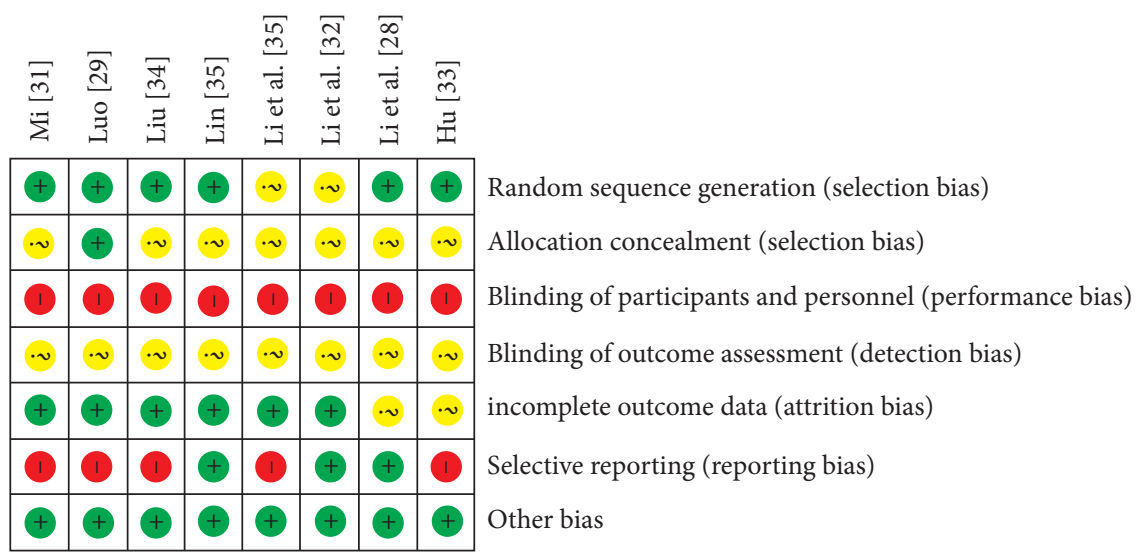

FIGURE 3: Risk of bias summary. 


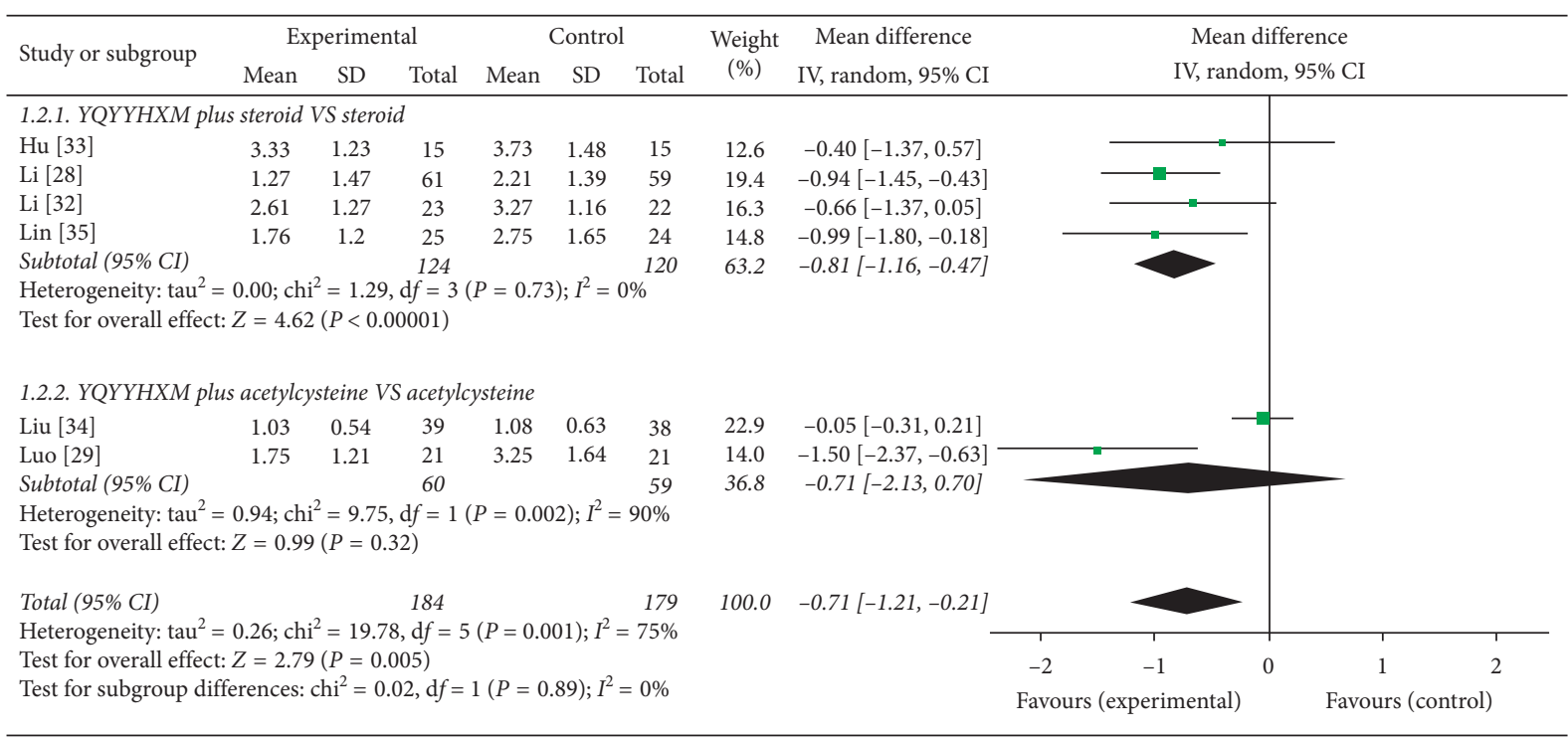

FIgURE 4: Meta-analysis for the change of cough of YQYYHXM group versus CWM group.

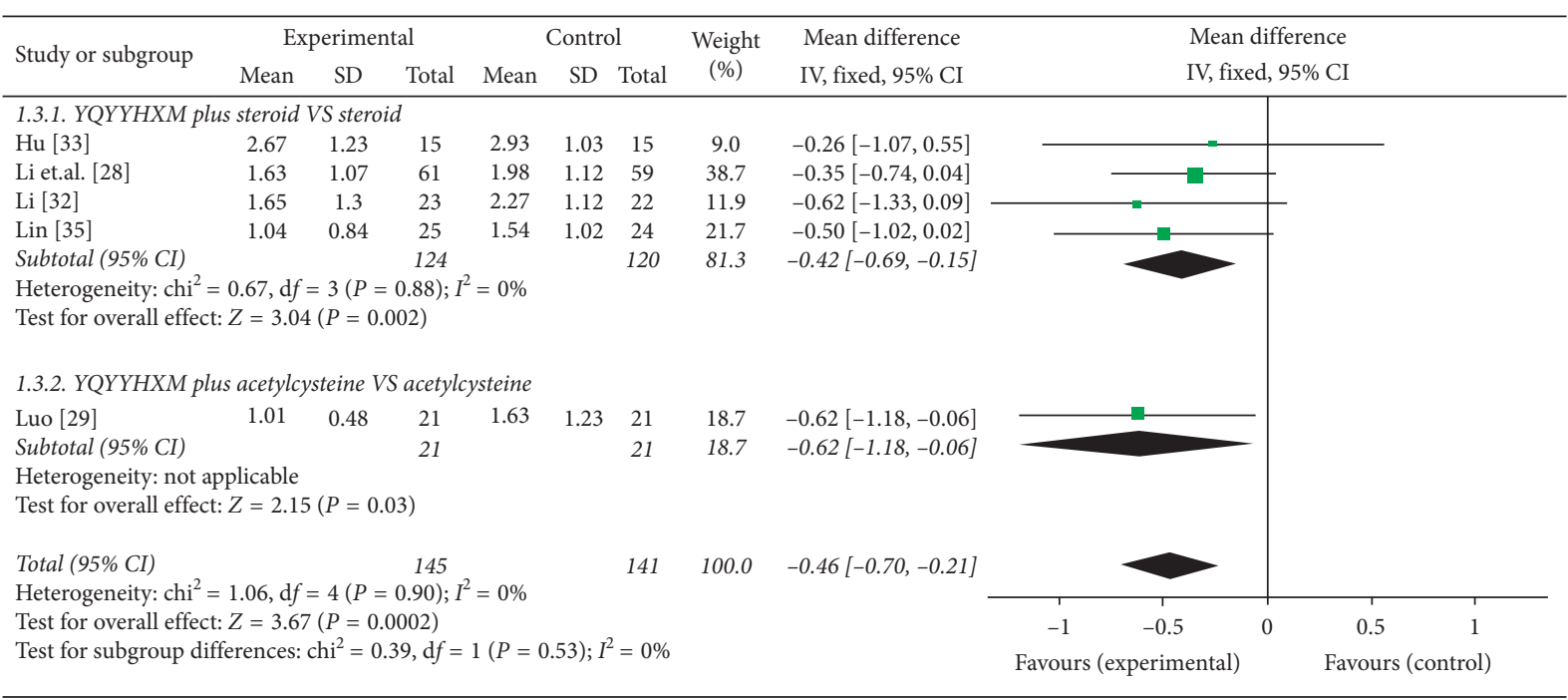

FIGURE 5: Meta-analysis for the change of chest pain of YQYYHXM group versus CWM group.

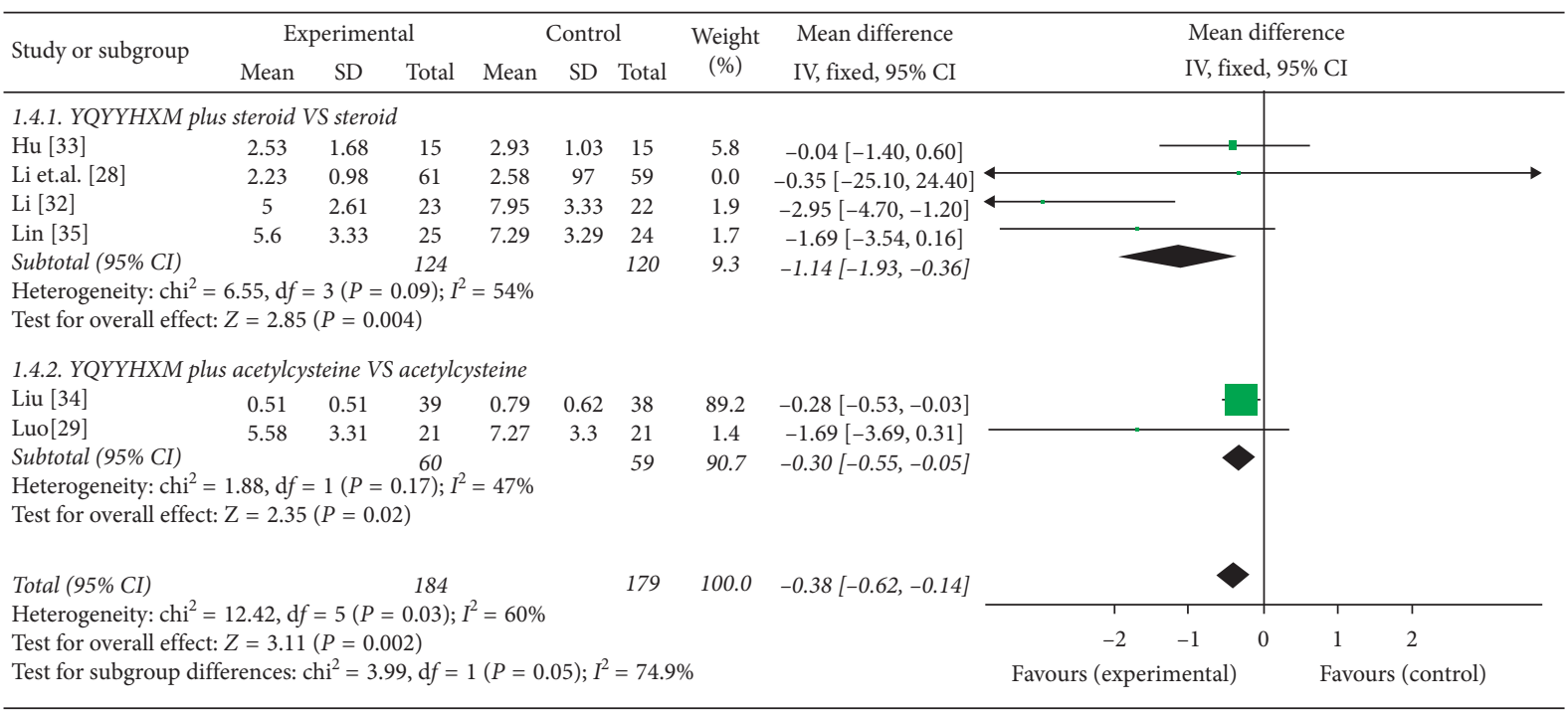




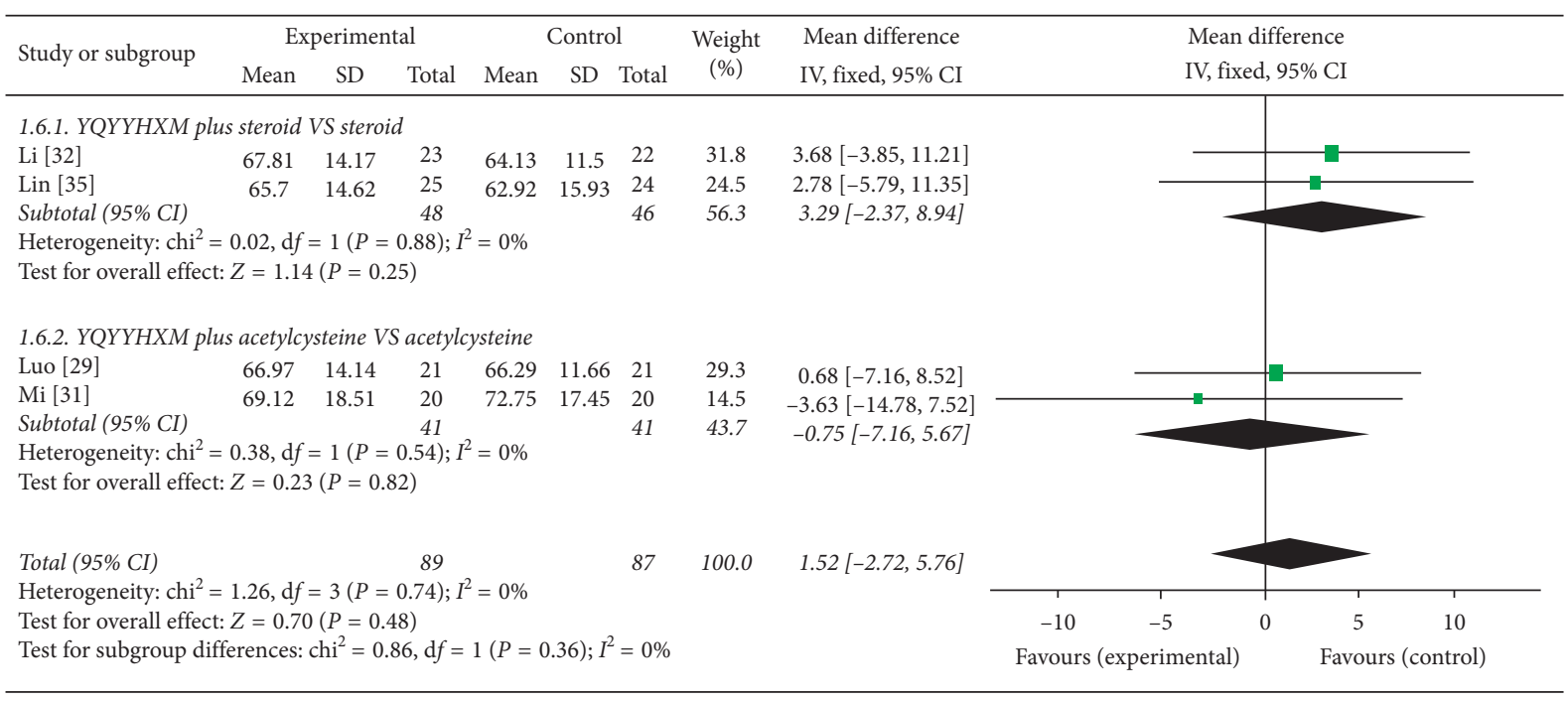

FIGURE 7: Meta-analysis for FVC of YQYYHXM group versus CWM group.

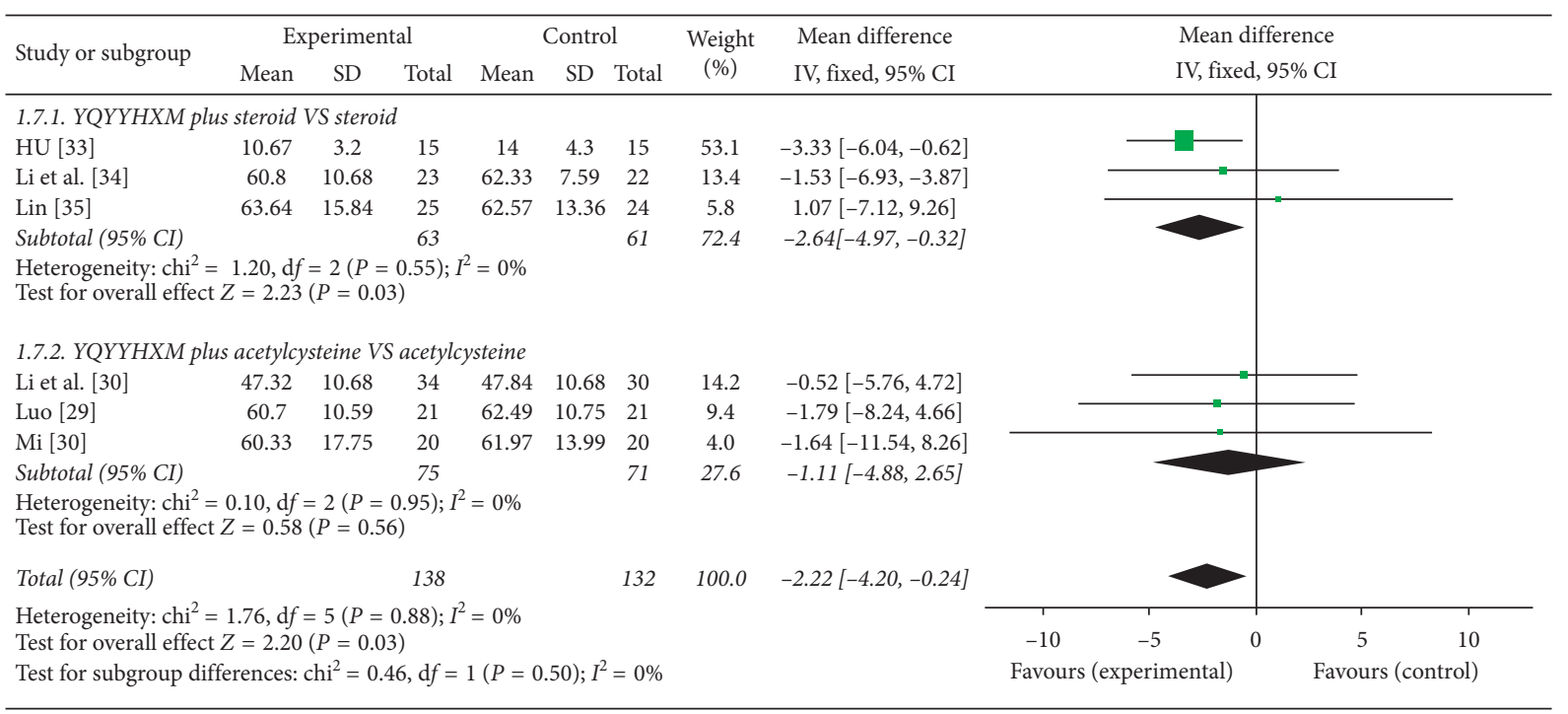

Figure 8: Meta-analysis for TLC of YQYYHXM group versus CWM group.

3.6.4. $6 M W D$. Five literatures $[28-31,34]$ carried out the data analysis of 6MWD. The heterogeneity among the RCTs was obvious (chi-square $=907.04, P<0.00001, I^{2}=100 \%$ ), and the random-effects model was used. The data analysis results illuminated that YQYYHXM combined CWM was better at improving the 6MWD than CWM alone ( $\mathrm{MD}=71.29,95 \%$ $\mathrm{CI}=[47.77,94.81], P<0.00001)$. Further subgroup analysis revealed that there was statistical significance of YQYYHXM combined with steroid $(P<0.00001)$ and acetylcysteine (chisquare $=520.12, P<0.00001, I^{2}=99 \%, \mathrm{MD}=62.49,95 \% \mathrm{CI}=$ [30.20, 94.78], $P<0.0001$ ) (Figure 10).

3.6.5. SGRQ Score. Five literatures [29, 31, 33, 35] conducted data analysis of SGRQ score. It was obvious that there was no statistical heterogeneity among these studies (chi-square $=1.16$, $\left.I^{2}=0 \%\right)$. So, the fixed-effects model was applied. Intuitive data showed that, compared with the western medicine group, the
TCM group was 3.60 times higher than that in the control group to improve the SGRQ score in the treatment of IPF $(\mathrm{OR}=3.60$, $95 \% \mathrm{CI}=[1.52,8.51], P=0.04)$. Further subgroup analysis revealed that there was no statistical significance for YQYYHXM combined with hormone $(P=0.19)$. However, it was statistically significant for YQYYHXM combined with acetylcysteine compared with acetylcysteine alone (chi-square $=0.51, I^{2}=0 \%$, $\mathrm{OR}=4.83,95 \% \mathrm{CI}=[1.54,15.14], P=0.007)$ (Figure 11). Moreover, the quality of evidence was moderate based on the GRADE approach in the statement of facts table for above outcomes. As shown in the table, the quality of change of cough, changes in shortness of breath, $\mathrm{PO}_{2}, 6 \mathrm{MWD}$ were moderate, and the rest were low or very low (Table 4).

3.6.6. Adverse Events. Three literatures [29, 31, 33, 35] reported the adverse events. Three studies of YQYYHXM combined with steroid compared with steroid alone 


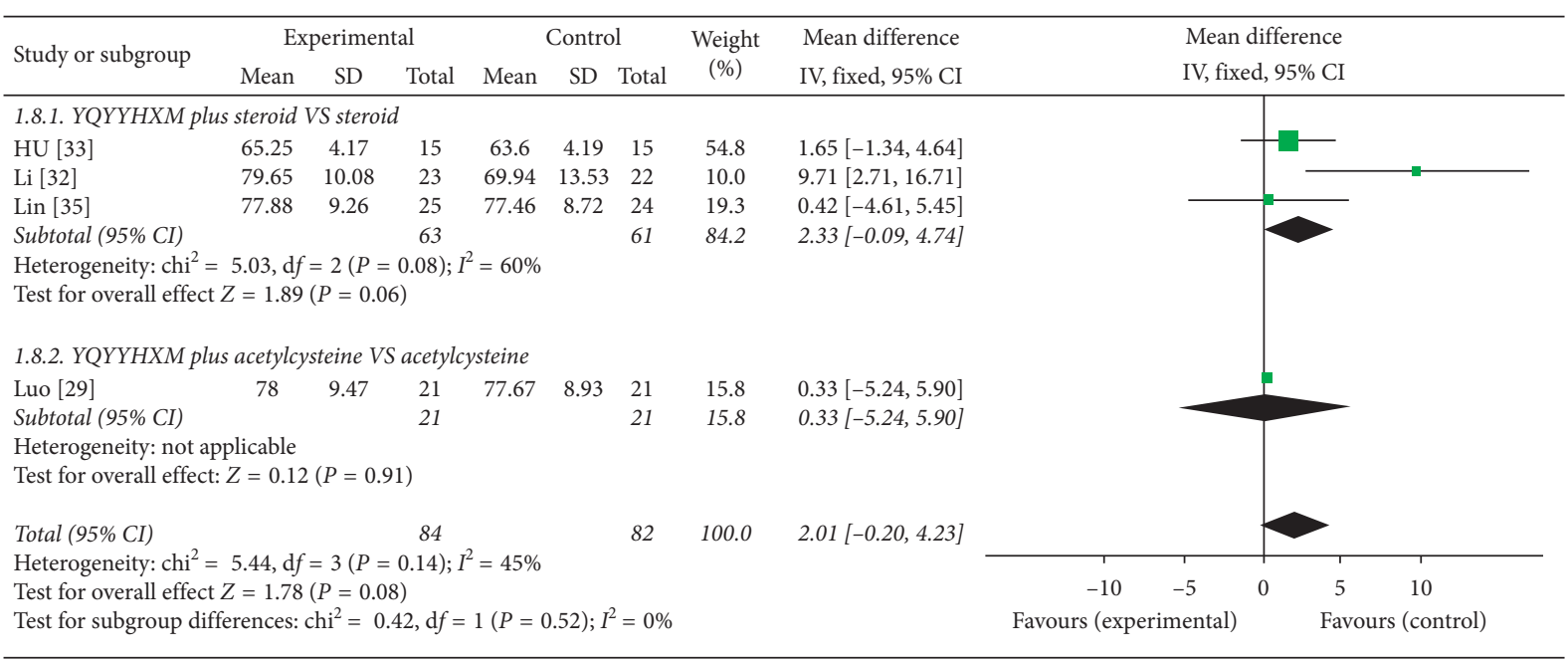

FIgURE 9: Meta-analysis for $\mathrm{PaO}_{2}$ of YQYYHXM group versus CWM group.

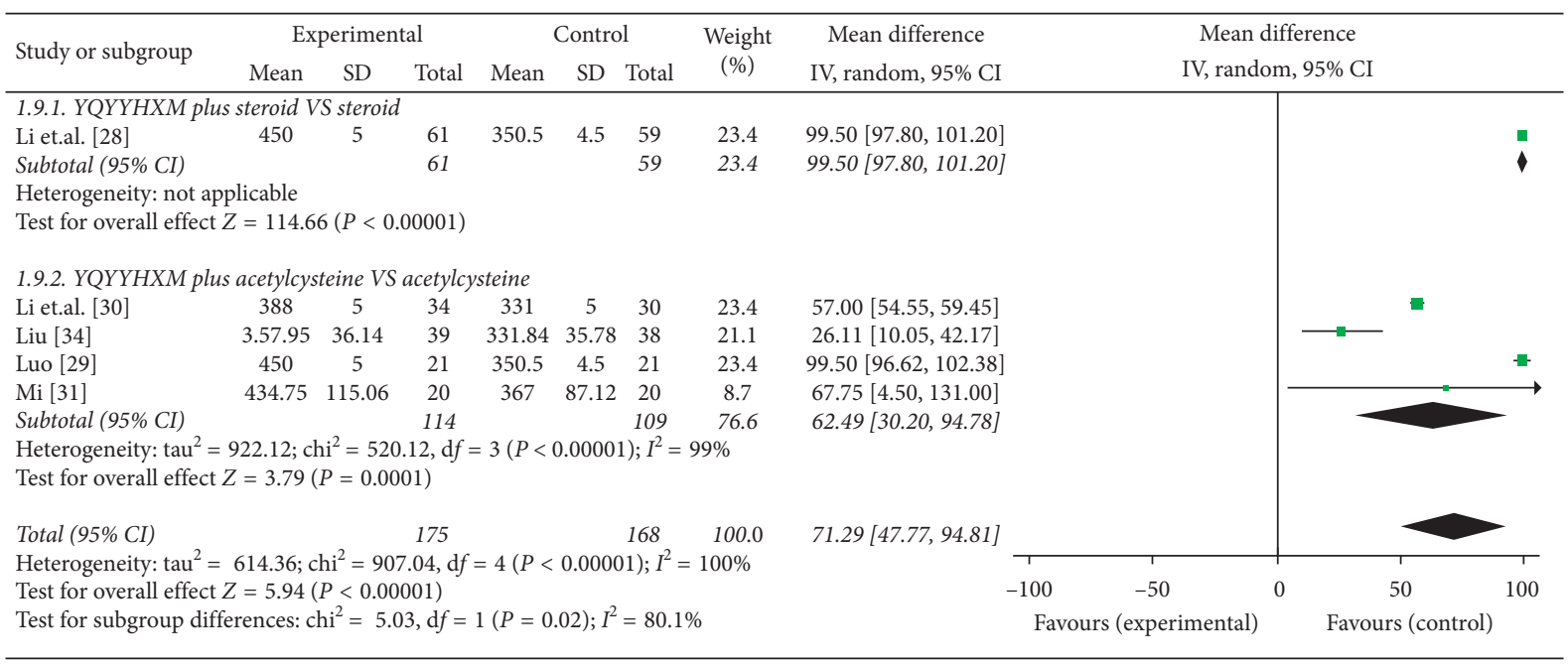

FIgURE 10: Meta-analysis for 6MWD of YQYYHXM group versus CWM group.

$[28,32,35]$ reported the details of adverse events. According to the analysis results, the heterogeneity was not found among the three studies (chi-square $=1.14, \quad P=0.57$, $\left.I^{2}=0 \%\right)$. So, the fixed-effects model was applied. Intuitive data showed that there were nineteen adverse events faced by patients who used steroid. And the results expressed that the probability of adverse events about YQYYHXM combined with steroid was more safer than steroid alone in the

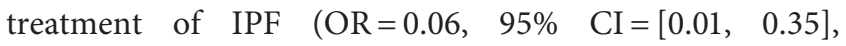
$P=0.001$ ) (Figure 12).

3.7. Evaluation of Heterogeneity and Sensitivity Analysis. Considering obvious heterogeneity in the comparison between YQYYHXM combined with CWM and CWM alone on the 6MWD, change of cough, and shortness of breath, we performed sensitivity analysis. Sensitivity analyses indicated that the result of cough and shortness of breath was stable. However, the results of only one study [34] were heterogeneous with other studies in 6MWD; although this study [34] was excluded, the results of high heterogeneity remained unchanged. Heterogeneity has not been solved, which may be the reason for the form of TCM or more rigorous compatibility (Figure 13).

3.8. Publication Bias. Due to the insufficient number of included studies (no more than 10 studies), we analyzed publication bias through Egger's test, and the results showed that there was no significant difference in cough, chest pain, shortness of breath, FVC, TLC, $\mathrm{PO}_{2}$, and SGRQ $(P>0.05)$. Nevertheless, there was statistical significance in the 6MWD $(P=0.013<0.05)$. In the process of extensive search of literature, it was found that almost all the published literatures reported positive results and almost no negative results. And all literatures were published in Chinese. The sources of publication bias may be due to the unpublished negative results or grey literature not identified in this review. 


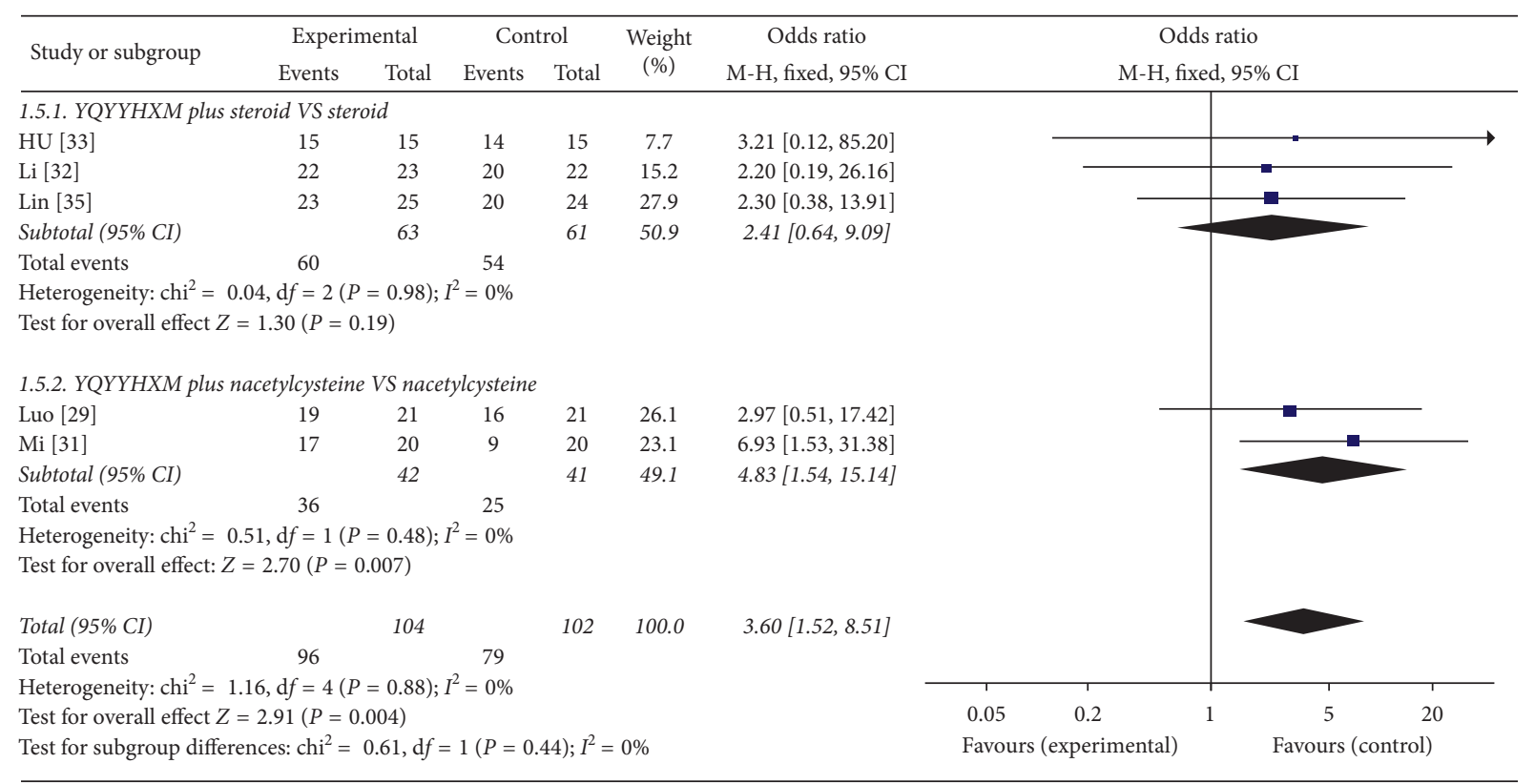

FIGURE 11: Meta-analysis for SGRQ score of YQYYHXM group versus CWM group.

TABLE 4: Statement of facts for all outcomes.

\section{YQYYHXM plus CWM vs. CWM}

Patient or population: patients with idiopathic pulmonary fibrosis; setting: all eligible patients with intervention therapy Intervention: (YQYYHXM, CWM)

\begin{tabular}{|c|c|c|c|c|c|}
\hline \multirow{2}{*}{ Outcome } & \multirow{2}{*}{$\begin{array}{l}\text { No. of participants } \\
\text { (RCTs) }\end{array}$} & \multirow{2}{*}{$\begin{array}{l}\text { Relative effect } \\
\quad(95 \% \mathrm{CI})\end{array}$} & \multicolumn{2}{|c|}{ Anticipated absolute effects (95\% CI) } & \multirow{2}{*}{$\begin{array}{l}\text { Quality of the } \\
\text { evidence } \\
\text { (GRADE) }\end{array}$} \\
\hline & & & CWM & CWM + YQYYHXM & \\
\hline $\begin{array}{l}\text { Change of cough } \\
\text { Follow-up: } 2-12 \\
\text { days }\end{array}$ & $\begin{array}{l}363 \\
(6 \mathrm{RCTs})\end{array}$ & & $\begin{array}{l}\text { The mean of change of } \\
\text { cough was } 1.08 \text { to } 3.73\end{array}$ & $\begin{array}{c}\text { MD } 0.71 \text { lower (1.21 to } 0.21 \\
\text { lower) }\end{array}$ & $\begin{array}{c}\oplus \oplus \oplus \mathrm{O} \\
\text { moderate }^{\mathrm{ab}}\end{array}$ \\
\hline $\begin{array}{l}\text { Changes of chest } \\
\text { pain } \\
\text { Follow-up: } 8-12 \\
\text { days }\end{array}$ & $\begin{array}{c}286 \\
\text { (5 RCTs) }\end{array}$ & & $\begin{array}{l}\text { The mean of chest pain was } \\
1.63 \text { to } 2.93\end{array}$ & $\begin{array}{c}\text { MD } 0.46 \text { lower }(0.7 \text { to } 0.21 \\
\text { lower })\end{array}$ & $\oplus \oplus \mathrm{OO}$ low \\
\hline $\begin{array}{l}\text { Changes in } \\
\text { shortness of breath } \\
\text { Follow-up:2-12 } \\
\text { days }\end{array}$ & $\begin{array}{l}363 \\
(6 \mathrm{RCTs})\end{array}$ & & $\begin{array}{l}\text { The mean of shortness of } \\
\text { breath was } 0.79 \text { to } 7.95\end{array}$ & $\begin{array}{c}\text { MD } 0.38 \text { lower }(0.62 \text { to } 0.14 \\
\text { lower })\end{array}$ & $\begin{array}{c}\oplus \oplus \oplus \mathrm{O} \\
\text { moderate }^{\mathrm{a}}\end{array}$ \\
\hline $\begin{array}{l}\text { FVC } \\
\text { Follow-up: } 12 \text { days }\end{array}$ & $\begin{array}{c}176 \\
(4 \text { RCTs }) \\
\end{array}$ & & $\begin{array}{c}\text { The mean of FVC was } 62.92 \\
\text { to } 72.25\end{array}$ & $\begin{array}{c}\text { MD } 1.52 \text { higher (2.72 lower to } \\
5.76 \text { higher })\end{array}$ & $\oplus \oplus$ OO low ${ }^{\mathrm{a}}$ \\
\hline $\begin{array}{l}\text { TLC } \\
\text { Follow-up: } 12 \text { days } \\
\end{array}$ & $\begin{array}{c}270 \\
(6 \text { RCTs }) \\
\end{array}$ & & $\begin{array}{c}\text { The mean of TLC was } 47.84 \\
\text { to } 62.57\end{array}$ & $\begin{array}{c}\text { MD } 2.22 \text { lower ( } 4.2 \text { to } 0.24 \\
\text { lower) }\end{array}$ & $\oplus \oplus \mathrm{OO}$ low $^{\mathrm{ac}}$ \\
\hline $\begin{array}{l}\mathrm{PO}_{2} \\
\text { Follow-up: } 12 \text { days }\end{array}$ & $\begin{array}{c}166 \\
\text { (4 RCTs) }\end{array}$ & & $\begin{array}{c}\text { The mean of } \mathrm{PO}_{2} \text { was } 77.46 \\
\text { to } 77.67\end{array}$ & $\begin{array}{c}\text { MD } 2.01 \text { higher }(0.2 \text { lower to } \\
4.23 \text { higher })\end{array}$ & $\begin{array}{c}\oplus \oplus \oplus \mathrm{O} \\
\text { moderate }^{\mathrm{a}}\end{array}$ \\
\hline $\begin{array}{l}\text { 6MWD } \\
\text { Follow-up: } \\
\text { 2-12days } \\
\end{array}$ & $\begin{array}{c}343 \\
(5 \text { RCTs })\end{array}$ & & $\begin{array}{l}\text { The mean of } 6 \mathrm{MWD} \text { was } \\
331 \text { to } 350.5\end{array}$ & $\begin{array}{c}\text { MD } 87.96 \text { higher }(86.71 \text { to } \\
89.21 \text { higher })\end{array}$ & $\begin{array}{c}\oplus \oplus \oplus \mathrm{O} \\
\text { moderate }^{\mathrm{ac}}\end{array}$ \\
\hline $\begin{array}{l}\text { SGRQ } \\
\text { Follow-up:2-12 } \\
\text { days } \\
\end{array}$ & $\begin{array}{c}206 \\
\text { (5 RCTs) }\end{array}$ & $\begin{array}{l}\text { OR } 3.6(1.52 \text { to } \\
8.51)\end{array}$ & $\begin{array}{l}\text { The mean of SGRQ } 114 \text { per } \\
1000 \text { (50 to } 144)\end{array}$ & 151 per 1000 (65 to 192$)$ & $\begin{array}{l}\oplus \text { OOO very } \\
\text { low }^{\text {a }}\end{array}$ \\
\hline
\end{tabular}

${ }^{*}$ GRADE Working Group grades of evidence. High quality: we are extremely confident for that the effect estimation lies close to true effect. Moderate quality: we have enough confidence for that effect estimation is likely to be close to the true effect. Low quality: we maintain partial confidence for that effect estimation may be obviously different from true effect. Very low quality: we have little confidence for that effect estimation is likely to be obviously different from true effect. Explanations. ${ }_{\mathrm{a}}$ No blinding. ${ }_{\mathrm{b}} \mathrm{High}$ heterogeneity. $c P<0.05$ in Egger's test. 


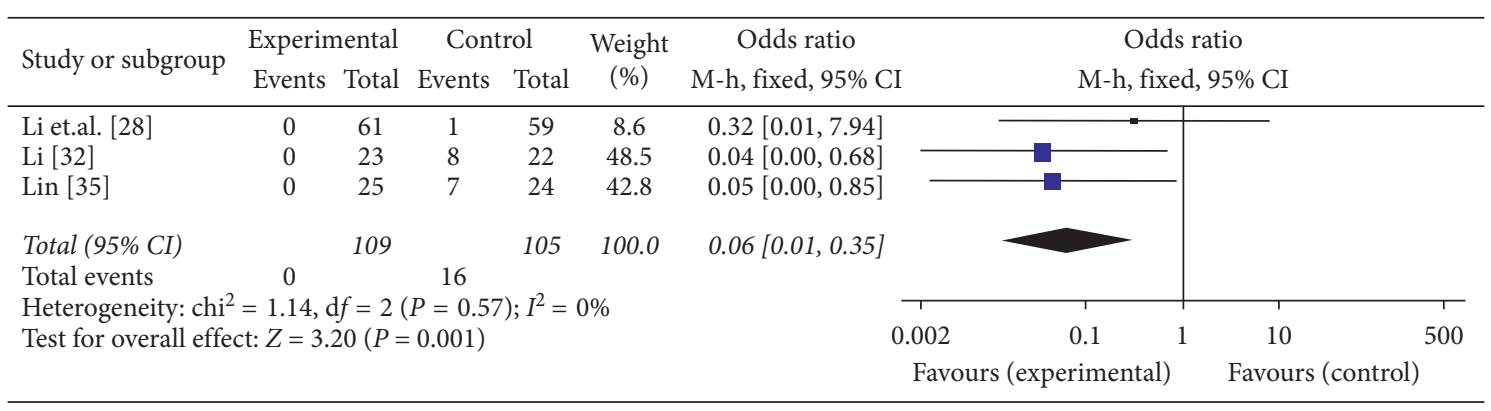

FIGURE 12: Meta-analysis for adverse events of YQYYHXM group versus CWM group.

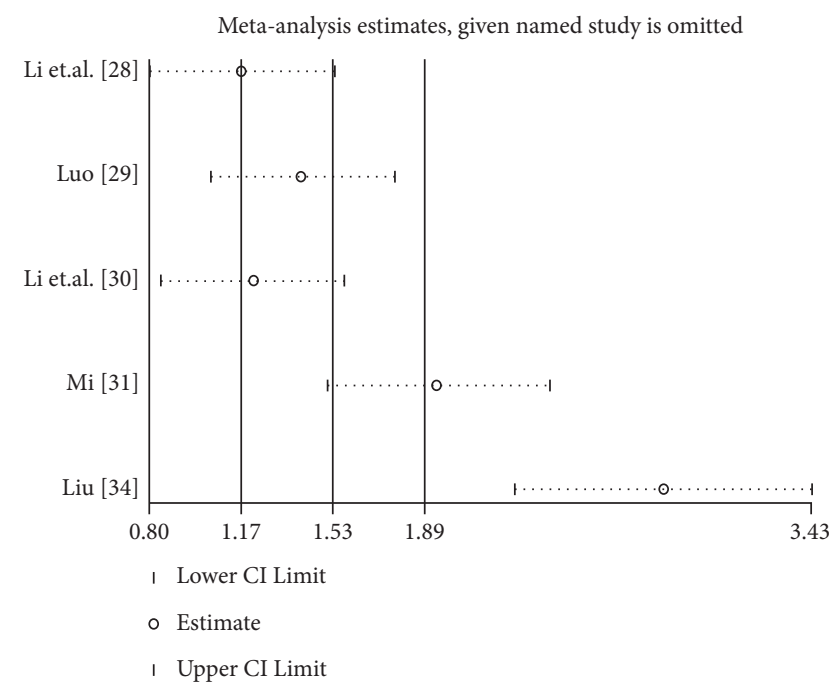

Figure 13: The sensitivity analysis of 6MWD.

\section{Pharmacological Research}

Nowadays, it is noteworthy to mention that there are more and more specific ingredients of the single herb of TCM which have been discovered to be related to the antipulmonary fibrosis. Maybe TCM is not just a simple compatibility, but the reason for its great effect is closely related to the many pharmacological ingredients it contains.

Astragalus membranaceus is one of the representative medicines of one of the representative herbs of tonifying qi. The study $[36,37]$ demonstrated that astragalus polysaccharides could reduce the expression of matrix metalloproteinase (MMP-2) and matrix metalloproteinase inhibitor (TIMP-1) in the lung tissue of rats with pulmonary fibrosis, thereby inhibiting the process of fibrosis. In vitro experiment found that the damage of lung ultrastructure with pulmonary fibrosis was notably reduced [38]. It significantly suppressed the abnormal increase of interleukin-4 (IL-4) and TNF- $\alpha$ levels, increased the level of interferon- $\gamma$ $($ IFN- $\gamma$ ), and contributed to the antifibrotic effects on pulmonary fibrosis by inhibiting TGF- $\beta 1$ production in the lung [39]. In vivo study probed the degrading effects of astragalin on epithelial to mesenchymal transition sensitized by ovalbumin, and the results revealed that astragalin can effectively alleviate bronchial fibrosis by suppressing autophagosome formation in airways [40].
Salvia miltiorrhiza Bge, one of the representative herbs of activating blood, Tanshinone IIA, has been shown to reduce TGF- $\beta 1$-induced fibrosis in rat fibroblasts and reduce BLMinduced pulmonary fibrosis. And one of the mechanisms may be involved with regulating pulmonary fibrosis related to inflammatory genes [41]. Lu et al. [42] found that Salvia miltiorrhiza was favorable for inhibiting abnormal increase of MDA and HYP and decrease of glutathione (GSH) in lung tissue homogenate of rats with pulmonary fibrosis, so salvia injection liquid has a positive effect of preventing pulmonary fibrosis in rats, but has no reversal effect on formed pulmonary fibrosis. Lin et al. [43] treated pulmonary fibrosis mice with salvia total phenolic acid which significantly reduced pulmonary fibrosis and alveolitis, and HYP levels were also obviously reduced. The in vivo research [44] demonstrated that Tanshinone IIA is beneficial for reducing BLM-induced pulmonary inflammatory cell infiltration, release of proinflammatory cytokine, and excessive collagen deposition in rats.

Adenophora stricta Miq. is one of the representative herbs of enriching yin. The relevant experiment confirmed that the work on imbalance of Th1/Th2 with Shashen Maidong decoction to alleviate inflammation and enhance the immune function $[45,46]$.

It is noteworthy to emphasize that the Feixiantong Decoction was applied in three studies accounting for 38 percent. Through clinical observation and animal experiments, the Feixiantong decoction composed of TCM with YQYYHXM could increase the IFN- $\gamma$ level in the serum and reduce the IL-4 level aimed to regulate the imbalance of Th1/ Th2 ratio and reduce the expression of Iand III type collagen fibers, thereby inhibiting ECM overexpression and delaying the process of fibrosis $[29,31,35]$. Related studies have also achieved considerable results under this theory, such as Shenks [41] was composed of TCM with the YQYYHXM. In vivo and in vitro studies have demonstrated that Shenks inhibits fibrosis by blocking the TGF- $\beta$ pathway and regulates the oxidant/antioxidant balance, whether prevention or treatment.

\section{Discussion}

The meta-analysis revealed that when YQYYHXM was adopted in combination with CWM, cough, chest pain, and shortness of breath of IPF patients improved significantly. After treatment with YQYYHXM combined with CWM, the 
SGRQ of IPF patients substantially enhanced. YQYYHXM also has positive effect on 6MWD and TLC, but the improvement on FVC was not obvious. In addition, YQYYHXM has no significance in improving $\mathrm{PaO}_{2}$. All the adverse events were reported in the control group especially in patients who used steroid. In the CWM group, there were 16 cases of adverse reactions, including 9 cases with moderate gastrointestinal reactions, 5 cases with elevated transaminase, and 2 cases with elevated blood glucose. And YQYYHXM combined with steroid in the experimental group reported no adverse reaction. It is important to highlight that it is not advisable to attribute the cause of adverse reactions to the dosage of the steroid. In fact, the dose of steroid is routine dose. Nevertheless, the security of the contrast is obvious, and whether this is the reason for reducing the adverse reactions of steroid or the cause of no adverse reactions caused by symptomatic treatment of TCM is worthy of attention in future studies.

However, this analysis also has some room for improvement. First, the sample size is a bit small, and most of the studies did not mention allocation concealment and blinding. Second, the specific composition of TCM based on the YQYYHXM method is still slightly different, which may be the reason that affects the difference in treatment effect. Third, considering the inherent characteristics of TCM with slow effect and the severity of IPF, the treatment course of all included studies is less than 3 months. For such a serious disease, the observed course is still short. It is difficult to achieve perfect treatment results. With respect to TCM, it is very common in China for the long-term treatment of severe diseases to achieve perfect treatment under the guidance of the principle of syndrome differentiation and treatment. Last, in the process of IPF treatment, the data analysis demonstrated that the tolerance of steroid is poor, resulting in a poorer treatment effect. Therefore, the tolerance is expected to be enhanced in future clinical work. Given those limitations, there is some enlightenment for us that the course of the IPF clinical study in the future should be extended to half a year or one year as much as possible. In addition, increasing need to explore the compatibility of TCM is also a crucial point for treatment of TCM, which is key for TCM to play the ideal effect. Furthermore, making full use of the advantages of good tolerance of TCM is also significant for fully exploiting the value of TCM in the future. Last, more and more high-quality, largescale, and long-term trials to provide more convincing evidence for the effectiveness and safety of YQYYHXM in the treatment of IPF are required.

\section{Conclusions}

YQYYHXM is more effective and safe as adjunctive treatment for patients with IPF, and it is necessary for further IPF research on YQYYHXM. In the future, high-quality, largescale, and long-term trials will be required to provide more credible evidence of YQYYHXM.

\section{Conflicts of Interest}

The authors declare that they have no conflicts of interest.

\section{Authors' Contributions}

Fan $\mathrm{Xu}$ and Min Zhou were responsible for all the work, including collecting documents, collating, data extraction, integration, acquisition, analysis, and interpretation of the data. Chao Ye and Qijun Liang provided valuable advice and guidance. Qiulan Pei and Hang Wen were involved in the writing of of this manuscript. Min Zhou participated in the whole process and wrote the manuscript. All authors were responsible for all aspects of the work throughout the entire process.

\section{Acknowledgments}

This study was supported by grants from the Chinese Medicine Evidence-Based Capacity Building Project (2019XZZX-LG005).

\section{References}

[1] V. Cottin, F. Capron, P. Grenier, and J.-F. Cordier, "Diffuse idiopathic interstitial pneumonias, international multidisciplinary consensus classification by the American Thoracic Society and the European Respiratory Society, principal clinico-pathological entities, and diagnosis," Revue des Maladies Respiratoires, vol. 21, no. 2, pp. 299-318, 2004.

[2] G. Raghu, H. R. Collard, J. J. Egan et al., "An official ATS/ERS/ JRS/ALAT statement: idiopathic pulmonary fibrosis: evidence-based guidelines for diagnosis and management," American Journal of Respiratory and Critical Care Medicine, vol. 183, no. 6, pp. 788-824, 2011.

[3] L. I. Wollin, V. Maillet, V. Quesniaux, A. Holweg, and B. Ryffel, "Antifibrotic and anti-inflammatory activity of the tyrosine kinase inhibitor nintedanib in experimental models of lung fibrosis," The Journal of Pharmacology and Experimental Therapeutics, vol. 349, no. 2, pp. 209-220, 2018.

[4] B. Magi, E. Bargagli, L. Bini, and P. Rottoli, "Proteome analysis of bronchoalveolar lavage in lung diseases," Proteomics, vol. 6, no. 23, pp. 6354-6369, 2006.

[5] P. B. Rottoli, M. G. Magi, S. Perari et al., "Cytokine profile and proteome analysis in BAL of patients with sarcoidosis, pulmonary fibrosis associated with systemic sclerosis and idiopathic pulmonary fibrosis," Proteomics, vol. 5, pp. 1423-1430, 2010.

[6] P. Cameli, A. Carleo, L. Bergantini, C. Landi, A. Prasse, and E. Bargagli, "Oxidant/antioxidant disequilibrium in idiopathic pulmonary fibrosis pathogenesis," Inflammation, vol. 43, no. 1, pp. 1-7, 2019.

[7] D. Chanda, E. Otoupalova, S. R. Smith, T. Volckaert, S. P. De Langhe, and V. J. Thannickal, "Developmental pathways in the pathogenesis of lung fibrosis," Molecular Aspects of Medicine, vol. 65, pp. 56-69, 2019.

[8] A. L. Olson, A. H. Gifford, N. Inase et al., "The epidemiology of idiopathic pulmonary fibrosis and interstitial lung diseases at risk of a progressive-fibrosing phenotype," European Respiratory Review, vol. 27, no. 150, Article ID 180077, 2018.

[9] V. Navaratnam, K. M. Fleming, J. West et al., "The rising incidence of idiopathic pulmonary fibrosis in the UK," Thorax, vol. 66, no. 6, pp. 462-467, 2011.

[10] P. Fernández, R. Evans, C. E. Daniels et al., "Incidence, prevalence, and clinical course of idiopathic pulmonary fibrosis: a population-based study," Chest, vol. 137, no. 1, pp. 129-137, 2010. 
[11] G. B. Raghu, Y. Rochwerg, C. A. Zhang et al., "An official ATS/ ERS/JRS/ALAT clinical practice guideline: treatment of idiopathic pulmonary fibrosis. An update of the 2011 clinical practice guideline," American Journal of Respiratory and Critical Care Medicine, vol. 192, no. 2, pp. e3-e19, 2015.

[12] L. Kolilekas, S. Papiris, and D. Bouros, "Existing and emerging treatments for idiopathic pulmonary fibrosis," Expert Review of Respiratory Medicine, vol. 13, no. 3, pp. 229-239, 2019.

[13] S. Fletcher, M. G. Jones, K. Spinks et al., "The safety of new drug treatments for idiopathic pulmonary fibrosis," Expert Opinion on Drug Safety, vol. 15, no. 11, p. 1483, 2016.

[14] L. J. Pang, J. P. Liu, and X. D. Lv, "Comparative effectiveness of 3 traditional chinese medicine treatment methods for idiopathic pulmonary fibrosis," Medicine, vol. 98, no. 30, Article ID e16325, 2019.

[15] R. Shao, F. J. Wang, M. Lyu et al., "Ability to suppress TGF$\beta$-activated myofibroblast differentiation distinguishes the anti-pulmonary fibrosis efficacy of two Danshen-containing Chinese herbal medicine prescriptions," Frontiers in Pharmacology, vol. 10, Article ID 412, 2019.

[16] X. L. Yu, Y. X. Zhang, X. H. Yang et al., "The influence of BuqiHuoxueTongluo formula on histopathology and pulmonary function test in bleomycin-induced idiopathic pulmonary fibrosis in rats," Evidence-based Complementary and Alternative Medicine, vol. 2018, Article ID 8903021, 13 pages, 2018.

[17] X. Chen, H Zhou, Y. B Liu et al., "Database of traditional Chinese medicine and its application to studies of mechanism and to prescription validation," British Journal of Pharmacology, vol. 149, no. 8, pp. 1092-1103, Article ID 0706945, 2006.

[18] J. Hu, J. Zhang, W. Zhao, Y. Zhang, L. Zhang, and H. Shang, "Cochrane systematic reviews of Chinese herbal medicines: an overview,” PLoS One, vol. 6, no. 12, Article ID e28696, 2011.

[19] Respiratory Society, "Chinese medical association guidelines for the diagnosis and treatment of idiopathic pulmonary (interstitial) fibrosis (draft)," Chinese Journal of Tuberculosis and Respiratory Diseases, vol. 25, pp. 387-389, 2002.

[20] R. Chen and P. Wang, "Discussion on the relationship between Feibi and idiopathic pulmonary fibrosis," Chinese Journal of Information on TCM, vol. 12, no. 6, pp. 90-91, 2005.

[21] W. 1. Tao, "Overview on traditional Chinese medicine in interstitial pneumonia treatment," Henan Traditional Chinese Medicine, vol. 34, no. 7, pp. 1421-1423, 2014.

[22] X. Wang and X. Li, "The microcirculation changes of pulmonary interstitial fibrosis were studied from the theory of collateral disease," Journal of Traditional Chinese Medicine, vol. 59, no. 9, pp. 743-745, 2018.

[23] Q. Yuan, L. J. Pang, Z. Hua et al., "Pathogenesis of idiopathic pulmonary fibrosis "Lung Qi Yin deficiency, phlegm stasis and collaterals"' Chinese Journal of Basic Medicine in Traditional Chinese Medicine, vol. 20, no. 7, pp. 893-921, 2014.

[24] "Chinese Society of Respiratory Medicine Draft guidelines for the diagnosis and treatment of idiopathic pulmonary interstitial fibrosis of the Chinese medical association respiratory society," Chinese Journal of Tuberculosis and Respiratory Diseases, vol. 2, no. 7, pp. 387-389, 2002.

[25] X. Y. Zheng, Guiding Principle of Clinical Research on New Drugs of Traditional Chinese Medicine, Chinese Medical Science and Technology Press, Beijing, China, 2002.

[26] L. C. Watters, T. E. King, M. I. Schwarz, J. A. Waldron, R. E. Stanford, and R. M. Cherniack, "A clinical, radiographic, and physiologic scoring system for the longitudinal assessment of patients with idiopathic pulmonary fibrosis1-3,"
American Review of Respiratory Disease, vol. 133, no. 1, p. 97, 1986.

[27] J. P. T. Higgins, D. G. Altman, P. C. Gøtzsche et al., "The Cochrane collaboration's tool for assessing risk of bias in randomised trials," British Medical Journal, vol. 343, no. 7829, Article ID d5928, 2011.

[28] Y. Li, X. J. Wang, and S. N. Zhang, "Observation on the curative effect of Feiwei granule on 61 cases of pulmonary interstitial fibrosis," Journal of Traditional Chinese Medicine, vol. 54, no. 6, pp. 496-499, 2013.

[29] H. L. Luo, "Clinical and experimental study on treatment of pulmonary fibrosis with pulmonary fibrillation," M.S. thesis, China Academy of Chinese Medical Sciences, Beijing, China, 2010.

[30] Z. H. Li, R. Dong, F. R. Xin et al., "Observation on therapeutic effect of Yangyin Yifei Tongluo pill on idiopathic pulmonary fibrosis," Journal of Liaoning College of Traditional Chinese Medicine and Pharmacy, vol. 17, no. 11, pp. 163-165, 2015.

[31] S. Mi, "Clinical and experimental study of Yiqi Tongbi method in treating idiopathic pulmonary interstitial fibrosis," M.S. thesis, Beijing University of Traditional Chinese Medicine, Beijing, China, 2012.

[32] Y. Y. Li, Y. P. Zhang, S. C. Wang et al., "Clinical study of Yiqi Tongluo method in treating idiopathic pulmonary fibrosis of pulmonary Obstruction and Qi-Yin deficiency," Shizhen Guoyi Guoyao, vol. 25, no. 3, pp. 630-632, 2014.

[33] X. L. Hu, "Clinical study on Yiqi Yangyin and Fei Luoluo therapy for idiopathic pulmonary interstitial fibrosis," M.S. thesis, Beijing University of Traditional Chinese Medicine, Beijing, China, 2007.

[34] Z. Y. Liu, "Clinical observation on treatment of 40 cases of pulmonary interstitial fibrosis with Yiqi Yangyin Huoxue Huayu method," Beijing Chinese Medicine, vol. 34, no. 4, pp. 312-314, 2017.

[35] L. Lin, "Clinical and experimental study on the treatment of idiopathic pulmonary interstitial fibrosis with traditional Chinese medicine Feixiantong," M.S. thesis, China Academy of Chinese Medical Sciences, Beijing, China, 2007.

[36] J. Li, Y. Zhang, and Y. J. Liu, "Effect of astragalus polysaccharide on cytokines and pulmonary tissue structure in rats with pulmonary fibrosis," Shizhen Guoyi Guoyao, vol. 22, no. 7, pp. 1684-1685, 2011.

[37] P. Zhang, J. P. Li, X. H. Xiao et al., "Effect of astragalus A on expression of experimental pulmonary fibrosis in rats," Advances in Modern Biomedicine, vol. 7, no. 6, pp. 860-862, 2007.

[38] Y. J. Liu, J. T. Li, J. Li et al., "Effect of astragalus on serum cytokines and lung ultrastructure in rats with pulmonary fibrosis," Chinese Journal of Immunology, vol. 24, no. 11, pp. 980-983, 2008.

[39] J. H. Kim, H. Y. Kim, S. Kim, J.-H. Chung, W. S. Park, and D. H. Chung, "Natural killer T (NKT) cells attenuate bleomycin-induced pulmonary fibrosis by producing interferon$\gamma$," The American Journal of Pathology, vol. 167, no. 5, pp. 1231-1241, 2005.

[40] I. H. Cho, Y. J. Choi, J. H. Gong et al., "Astragalin inhibits autophagy-associated airway epithelial fibrosis," Respiratory Research, vol. 16, no. 1, p. 51, 2015.

[41] H. Chu, Y. Shi, S. Jiang et al., "Treatment effects of the traditional Chinese medicine Shenks in bleomycin-induced lung fibrosis through regulation of TGF-beta/Smad3 signaling and oxidative stress," Scientific Reports, vol. 7, no. 1, p. 2252, 2017.

[42] S. J. Lu, Y. N. Liu, and H. Z. Wang, "Experimental study of salvia miltiorrhiza on pulmonary fibrosis induced by 
bleomycin," Chinese Journal of Clinical Pharmacology and Therapeutics, vol. 10, no. 5, pp. 514-517, 2005.

[43] J. Lin, Y. Z. Feng, Z. LGu et al., "Effect of salvia total phenolic acid on bleomycin-induced pulmonary fibrosis in mice," Chinese Herbal Medicine, vol. 39, no. 3, pp. 400-403, 2008.

[44] H. He, H. Tang, L. Gao et al., "Tanshinone IIA attenuates bleomycin-induced pulmonary fibrosis in rats," Molecular Medicine Reports, vol. 11, no. 6, pp. 4190-4196, 2015.

[45] Y. Yang and Y. Zhou, "Shashen-Maidong decoction-mediated IFN- $\gamma$ and IL- 4 on the regulation of Th1/Th2 imbalance in RP rats," BioMed Research International, vol. 2019, Article ID 31341902, 2019.

[46] L. Fang, Z. Yong, H. L. Chao et al., "Effect of Yiqi Yangyin Jiedu recipe on $t$ cell subsets and Th1/Th2 drift in patients with non-small cell lung cancer," Journal of Practical Internal Medicine of Traditional Chinese Medicine, vol. 25, no. 5, pp. 8-10, 2011. 